\title{
Multi-criteria method of selection the way of conducting railway traffic on the open line for modernized and revitalized railway lines
}

\author{
Piotr Gołębiowski ${ }^{1}$, Marianna Jacyna ${ }^{1}$, and Jolanta Żak ${ }^{1, *}$ \\ ${ }^{1}$ Warsaw University of Technology, Faculty of Transport, 00662 Warsaw, Poland
}

\begin{abstract}
Nowadays, thanks to funds coming from various sources - including the European Union, intensive modernization and revitalization works regarding railway transport infrastructure are carried out. These works include both the railway surface and the change in the way of conducting railway traffic on both open lines and operating control posts. During modernization and revitalization, efforts are being made to introduce more and more new solutions in both mentioned areas. However, there is no multicriteria method that would allow to assess which method seems to be the most advantageous. The aim of this article is to present a multicriteria method of choosing the method of conducting railway traffic on the open line for modernized and revitalized railway lines. It should be noted that the basic group of criteria in the method applies to the organization of railway traffic. The article discusses the basic issues regarding the modernization and revitalization of railway lines, ways of conducting railway traffic on open lines and multi-criteria assessment methods. A multicriteria method for selecting the method of conducting trains was presented and it was verified for a selected railway line in Poland.
\end{abstract}

\section{Introduction}

The most important problem regarding railway transport is the need to maintain the highest level of safety. It is affected by the condition of tracks and turnouts, as well as control command and signalling equipment. The bad condition of the above-mentioned elements is the most common cause of accidents on the railways. Additional factors that affect many accidents are exceeding the speed limit by drivers [1-2], as well as poor state of rolling stock.

In order to ensure the level of safety [3-6] and improve the quality of provided services [7-9], the infrastructure manager constantly monitors any irregularities related to the condition of railway infrastructure. The activities related to the supervision of the railway line included [10]:

- control covering the entire length of tracks,

- control of sections under extraordinary circumstances

(e.g. during floods, snowfall, rail ruptures),

- protection of dangerous places,

- viewing tours.

Visual inspection and assessment of the used surface during supervision are carried out using two techniques:

- surface inspection, i.e. visual assessment of the condition of the railway's elements and unit measurement of worn or damaged elements,

- measurement of the track made using appropriate measuring instruments, i.e. trolleys or measuring wagons.
According to the assessment of the technical condition of railway lines in Poland, about 15,000 km of railway tracks has significantly reduced operating parameters compared to the construction parameters [11]. Their technical condition requires repair related to the replacement of individual components or the entire track surface.

Lack of modernization of the existing infrastructure by the manager and failure to remove the problems [12] carries the consequences of introducing numerous speed limits [13-14] and the emergency mode of traffic control devices, e.g. by means of a substitute signal. The consequence of this is the slow removal of existing defects associated with the lack of financial resources and qualified personnel responsible for security. Therefore, the lack of a quick reaction of the manager in this respect results in an increase in the number of restrictions (i.e. speed reduction, closure of railway tracks) on the given lines, and consequently an increase in the travel time of trains and a reduction in the capacity of railway lines.

One of the decision problems in the modernization or revitalization of a railway line is the choice of the way of conducting railway traffic on adjacent routes. There are no methods that precisely determine the way of traffic on railway lines. The aim of the article is to develop a multicriteria method [15-19] of selection the way of conducting railway traffic on the open line for modernized and revitalized railway lines. The article presents the problems of revitalization and 
modernization of railway lines. The rules of running trains on the open lines are discussed and the multicriteria method for selecting the method is presented. An example of the method's operation based on the Ustronie Morskie station in the West Pomeranian Voivodeship is presented. The scientific novelty in the article is an attempt to use the selected method of multicriteria assessment for choosing the best way of conducting railway traffic on the open lines for a selected operating control post. Another novelty is the use of the multi-criteria assessment method with interval assessments in rail transport.

\section{Problems of revitalization and modernization of railway lines}

The technical condition of many railway lines is not the best. Thanks to funds obtained from various sources, there is a chance to renew individual sections of the line so that the quality of provided services is on the high level. Renewal of the railway line can be done in two ways: revitalizing it or modernizing it.

Revitalization is a comprehensive and in-depth set of activities carried out to improve infrastructure conditions [1]. The purpose of the performed activities is to restore the value and significance of degraded areas and objects (in the event of losing their original functions) to improve the economic, social and environmental situation.

Modernization [20] includes the execution of construction works in order to modernize and improve the infrastructure, striving to increase its utility value. It should be noted that the commonly used concept of "modernization" does not legally appear in the Construction Law. The modernization process includes the following works [21]:

- renovation - execution of construction works in a given place or facility (not included in the set of maintenance operations) in order to restore its original condition using the same or other building materials (e.g. replacement of track surface elements without changing their technical parameters),

- reconstruction - construction works, as a result of which certain technical parameters change, not including surfaces and fixed dimensions, i.e. length, height and width (e.g. reconstruction of the track system, change of track geometry, replacement of track elements with another type),

- extension - execution of construction works as a result of which there are changes in the parameters of a given building, i.e.: building area, cubic volume, height, length and width (e.g. extension of the second railway track, extension of passenger stops to stations).

Therefore, revitalization, in contrast to modernization, which assumes improvement of the railway line parameters and increasing the permissible speed of trains, is only a reconstruction of the original condition of the railway line.

\section{Rules for conducting traffic on railway open lines}

\subsection{General assumptions}

During the modernization or revitalization of the railway line, the decision-maker is faced with the need to decide which way of conducting the railway traffic on the open lines is appropriate for the analysed case. A number of factors have to be taken into consideration, which influence the choice of the best solution [7, 22]. During making the decision, it is necessary to remember that when conducting of trains traffic along the open line, several rules are necessary to take into account:

- on the double track open line, the train traffic should be conduct on the right track, looking in the direction of the train; from this rule there are many exceptions - traffic can also be carried out on the left track when traffic control devices allow or require such a necessity,

- on each track of the open line or block section in one time can be only one train,

- the station inspector can send a train from a traffic post if the adjacent trail or distance is free; in addition, it must be ensured that the traffic officer in the neighbouring post does not train on the train track,

- about duty of the open line station inspector is informed on the basis of the line blocking devices state or an agreement with the station inspector of the neighbouring operating control post using radio communication devices (announcing of trains),

- permission on departure of the train station inspector may issue on the basis of receiving a permit from a neighbouring operating control post for the train's departure or other indications [1],

- when the devices do not allow for the train departure on the open line onto the permit signal, it can be sent to a substitute signal or a written order under certain conditions,

- when the line blocking devices do not work properly, carry out the traffic based on announcements by means of telephone communication.

\subsection{Conducting of train traffic based on telephone announcements}

The first way to conduct train traffic on the open lines is telephone train announcements. In this method, traffic is secured by telephone communication of the station inspectors and making appropriate notes in the Traffic Log. The rules for announcing trains should be defined for two situations.

The first one concerns the open line on which a single-track two-way traffic is conducted. This type of traffic can be carried out for two cases: on single-track open lines and double-track open lines, where one or two tracks allow on two-way traffic. For this situation, the rules for announcing trains are as follows:

- in order to departure a train on the open line, first you must call for a train request by phone (the station inspector from the train departure post is calling the station inspector from the neighbouring post), 
- if there are no obstacles to driving, the station inspector of the neighbouring post gives permission to departure a train (during a telephone conversation in which the permit was requested),

- when the train leaves the departure post, it is necessary to announce the departure of the train to the station inspector of the neighbouring post by phone,

- when the train has arrived at the arrival post, it is necessary to confirm the arrival of it to the departure operating control post by phone.

The second situation concerns the open line on which double-track one-way traffic is conducted. This type of traffic can be carried out on double-track open lines along each track. Therefore, for each track a strictly defined train direction applies. With this kind of traffic, it is certain that no train was sent to the non-fundamental track. For this situation, the rules for announcing trains are as follows:

- due to the above-mentioned premises, there is no need to request a permit and give a permit,

- when the train leaves the departure post, it is necessary to announce the departure of the train to the station inspector of the neighbouring post by phone,

- when the train leaves the departure post, it is necessary to announce the departure of the train to the station inspector of the neighbouring post by phone.

As already mentioned, train announcements are made via short phone calls using pre-conceived telephone plans, having content strictly defined in [23]. Telephone announcements may also be carried out using radio communication devices.

\subsection{Conducting of train traffic based on manual line block}

The second way to conduct train traffic on the open lines is valid when the operating control posts and open line are equipped with devices of a manual block. In this method, the traffic is secured by telephone communication of station inspector, handling of manual block devices and making appropriate notes in the Traffic Log. The rules for announcing trains are also defined for two situations - as for telephone announcements.

When single-track two-way train movement is in force, the following line blocking devices are used - the device situate at the entrance end of the section to release the entry signal and device situate at the leaving end of the section to release the entry signal, in addition, a telephone request and give permission should be made and the permission mechanism should be handled. After the messages concerning the request and permission is exchanged, the station inspector giving the permission blocks the permission mechanism, which unblocks the permission mechanism of the station inspector requesting the permit. Then, after leaving the train from the leaving post, station inspector blocking device situate at the entrance end of the section to release the entry signal, which causes the device situate at the leaving end of the section to release the entry signal of the receiving unblock and has an interpretation of the time of departure. After the train entry to the receiving station, the station inspector blocks the device situate at the leaving end of the section to release the entry signal, which unblocks the device situate at the entrance end of the section to release the entry signal of the station inspector and is interpreted as the arrival announcement.

When double-track one-way train traffic applies, the following devices of a manual block are used - the device situate at the entrance end of the section to release the entry signal and device situate at the leaving end of the section to release the entry signal referring to a specific track. The station inspector has at his disposal the device situate at the entrance end of the section to release the entry signal, which blocking causes unblocking of the device situate at the leaving end of the section to release the entry signal in the receiving operating control post and has an interpretation of the announcement of the time of departure. The blocking of the device situates at the leaving end of the section to release the entry signal by the station inspector accepts the device situate at the entrance end of the section to release the entry signal of the station inspector and is interpreted as the arrival announcement.

It should be noted that manual block does not provide information about the train number that has been sent to the open line. Therefore, on the double-track open line, when one-way traffic is carried out, after each of them is sent, the number should be forwarded by phone. The information is given before blocking the device situate at the entrance end of the section to release the entry signal.

\subsection{Conducting of train traffic based on automatic electric block system}

The second way to conduct train traffic on the open lines is valid when the operating control posts and open line are equipped with devices of automatic electric block system. In this method, the traffic is secured by telephone communication of station inspector, handling of automatic electric block system devices and making appropriate notes in the Traffic Log.

The essence of the automatic electric block system is that it allows dividing the open line into many block sections. At each of the sections, theoretically, there can be only one train at one time. However, it should be noted that you cannot talk about traffic flow. In order to keep it, subsequent trains should be sent out of the operating control post in such a way that the indication of the block signal would allow you to drive at the maximum permitted speed for this and the next block signal (so-called green driving).

Block signal of automatic electric block system are not man operated. The signals on them appear automatically on the basis of the information about the occupancy of the block section, which is protected by the given block signal. The block system can only be turned on in one direction at one time. It can be set permanently (if the automatic electric block system function allows it) - then it is not necessary to re-engage it in the same direction after the train has passed, or only for passing one train (for an unprivileged direction). When a given 
track is adapted to conduct two-way traffic, the block signal in the second direction will be extinguished, except for the last block signal acting as a warning signal. On single track open lines equipped with devices of automatic electric block system, which are adapted to carry out two-way traffic, the automatic electric block system switches off after running off the open line of the last train. For such a case, re-setting the direction of automatic electric block system is possible only after obtaining permission from the station inspector. After the train is sent to the open line towards the neighbouring station inspector, he is obliged to provide information to the neighbouring station about the train number by phone.

In case the devices of automatic electric block system do not work properly, enter the train announcements by phone. Movement of trains then takes place at the interval of follow-on stations - only one train running in a given direction at a given moment can be on the route.

\section{The algorithm of multi-criteria method of selection the way of conducting railway traffic on the open lines}

\subsection{The steps of algorithm}

To choose the best solution use of the SAW interval method with objective weights obtained by interval entropy [23-25]. This method is one of methods, which are used for solving multi-criteria optimization tasks. The SAW method was chosen for solving this problem because of the simplicity of the calculations and because of the possibility of using interval evaluations of variants against individual criteria.

SAW interval method consists of the following steps:

Step 1. Construction of the interval decision matrix ( V - set of variants, $\mathbf{C}$ - set of criteria):

$$
\mathbf{X}=\left[\left[\underline{x}_{v c}, \bar{x}_{v c}\right]\right] v \in \mathbf{V}, c \in \mathbf{C}
$$

Step 2. Normalization of the interval decision matrix

$$
\left[\underline{n}_{v c}, \bar{n}_{v c}\right]=\left\{\begin{array}{c}
{\left[\frac{\underline{x}_{v c}}{\sum_{v \in \mathbf{V}}\left(\underline{x}_{v c}+\bar{x}_{v c}\right)}, \frac{\bar{x}_{v c}}{\sum_{v \in \mathbf{V}}\left(\underline{x}_{v c}+\bar{x}_{v c}\right)}\right] \text { (stimulant) }} \\
{\left[\frac{\left(\bar{x}_{v c}\right)^{-1}}{\left.\sum_{v \in \mathbf{V}}\left(\underline{x}_{v c}\right)^{-1}+\left(\bar{x}_{v c}\right)^{-1}\right)}, \frac{\left(\underline{x}_{v c}\right)^{-1}}{\left.\sum_{v \in \mathbf{V}}\left(\underline{x}_{v c}\right)^{-1}+\left(\bar{x}_{v c}\right)^{-1}\right)}\right] \text { (destimulant) }}
\end{array}\right.
$$

Step 3. Determination of objective weights

a) Determination of the entropy vector for each criterion:

$$
\begin{aligned}
& \mathbf{e}=\left[\left[\underline{e}_{c}, \bar{e}_{c}\right]: c \in \mathbf{C}\right] \\
& \underline{e}_{c}=\min \left\{-(\ln \overline{\overline{\mathbf{V}}})^{-1} \sum_{v \in \mathbf{V}}\left(\underline{n}_{v c} \ln \underline{n}_{v c}\right),-(\ln \overline{\overline{\mathbf{V}}})^{-1} \sum_{v \in \mathbf{V}}\left(\bar{n}_{v c} \ln \bar{n}_{v c}\right)\right\} \\
& \bar{e}_{c}=\min \left\{-(\ln \overline{\overline{\mathbf{V}}})^{-1} \sum_{v \in \mathbf{V}}\left(\underline{n}_{v c} \ln \underline{n}_{v c}\right),-(\ln \overline{\overline{\mathbf{V}}})^{-1} \sum_{v \in \mathbf{V}}\left(\bar{n}_{v c} \ln \bar{n}_{v c}\right)\right\}
\end{aligned}
$$

b) Determination of the volatility level vector for each criterion according to the formula:

$$
\mathbf{d}=\left[\left[\underline{d}_{c}, \bar{d}_{c}\right] \equiv\left[1-\bar{e}_{c}, 1-\underline{e}_{c}\right]: c \in \mathbf{C}\right]
$$

c) Determination of the vector of objective weights

$$
\mathbf{w}=\left[\left[\underline{w}_{c}, \bar{w}_{c}\right] \equiv\left[\frac{\underline{d}_{v c}}{\sum_{c \in \mathbf{C}}\left(\underline{d}_{v c}+\bar{d}_{v c}\right)}, \frac{\bar{d}_{v c}}{\sum_{c \in \mathbf{C}}\left(\underline{d}_{v c}+\bar{d}_{v c}\right)}\right]: c \in \mathbf{C}\right]
$$

Step 4. Designation for each variant of the linear combination of normalized assessments against criteria and weight vector.

Step 5. Line ordering of results and selection of the final variant.

\subsection{The assumption of variants definition}

In the multicriteria method of selection the way of conducting railway traffic on the open line for modernized and revitalized railway lines, many variants are defined and then evaluated on the basis of a series of partial criteria. Ten variants of railway traffic will be analysed in the developed method:

(1) telephone announcements of trains - single-track two-way train movement $(v=1)$,

(2) telephone announcements of trains - double-track one-way train movement $(v=2)$,

(3) manual line block - single-track two-way train movement $(v=3)$,

(4) manual line block - double-track one-way train movement $(v=4)$,

(5) two-state automatic electric block system - singletrack two-way train movement $(v=5)$,

(6) two-state automatic electric block system - doubletrack one-way train movement $(v=6)$,

(7) three-state automatic electric block system - singletrack two-way train movement $(v=7)$,

(8) three-state automatic electric block system - doubletrack one-way train movement $(v=8)$,

(9) four-state automatic electric block system - singletrack two-way train movement $(v=9)$,

(10) four-state automatic electric block system - doubletrack one-way train movement $(v=10)$.

As criteria in the multicriteria method of selection the way of conducting railway traffic on the open line for modernized and revitalized railway lines, it is proposed to use:

- time of agreement to accept the train $(c=1)$ - it means the time which elapses from the moment when the neighbouring operating control post starts calling on the announcing links to the moment of agreement and termination of the conversation and possibly the time of blocking the permission mechanism and switching on the block direction,

- time of receiving information about the departure of the train $(c=2)$ - it means the time which elapses from the moment when the neighbouring post starts calling on the announcing links to the moment of receiving information 
about the departure of the train and termination of the conversation and eventually the time of unblocking the device situate at the leaving end of the section to release the entry signal,

- time of preparing the train entry $(c=3)$ - it means the time which elapses from the moment of start of activities related to the entry of the train until the start of preparation of the path,

- preparation time of the path $(c=4)$ - it means the time it takes for the physical preparation of the path (taking into account, among others, cooperation with other persons involved in the conducting of trains traffic),

- driving surveillance $(c=5)$ - it means the observation time of the train entering,

- end time of the path $(c=6)$ - it means the time when the path of the train is physically finished,

- time of activities related to the end of the train entry $(c=7)$ - it means the time that elapses from the moment the path is completed to the end of the train entry documenting,

- time of announcing the arrival of the train $(c=8)-$ it means the time which elapses from the moment when the calling of the neighbouring post on the announcing links starts until the information on the departure of the train has been forwarded and the conversation has been terminated, and possibly the blocking time of the device situate at the leaving end of the section to release the entry signal,

- time of requesting permission to send a train $(c=9)$ - it means the time which elapses from the moment when calling the neighbouring post on the announcing links to the moment of agreement and termination of the conversation, and possibly the time of unblocking the permission mechanism and switching on the block direction,

- time of train departure preparation $(c=10)$ - it means the time that elapses from the start of activities related to the entry of the train until the start of the preparation of the path,

- preparation time of the path $(c=11)$ - it means the time it takes for the physical preparation of the path (taking into account, among others, cooperation with other persons involved in the conducting of trains traffic),

- driving surveillance $(c=12)$ - it means the observation time of the train entering,

- end time of the path $(c=13)$ - it means the time when the path of the train is physically finished,

- time of activities related to the end of the train departure $(c=14)$ - it means the time that elapses from the moment the path is completed to the end of the train departure documenting,

- time of giving information about the departure of the train $(c=15)$ - it means the time which elapses from the moment when the calling of the neighbouring post on the announcing links starts until the information on the departure of the train has been forwarded and the conversation has been terminated, and possibly the blocking time of the device situate at the entrance end of the section to release the entry signal,

- time of receiving information about the arrival of the train $(c=16)$ - it means the time which elapses from the moment when the neighbouring post starts calling on the announcing links to the moment of receiving information about the arrival of the train and termination of the conversation and eventually the time of unblocking the device situate at the entrance end of the section to release the entry signal,

- the sum of times from the criteria from $c=1$ to $c=16$ $(c=17)$ - it means the time of absorption of the station inspector associated with the passage of one train by the station; this is the time when the station inspector cannot do other activities.

The selection of criteria in the method allows to assess the time necessary to pass one train - that is activities related to the acceptance and dispatching of the train. On this basis, the capacity of the traffic post can be estimated. If we analyse an operating control post where the train ends or starts a run, certain activities will not be taken into account.

Data for calculating the value of individual criteria should be adopted in accordance with the local conditions of the analysed traffic station [23]. The key documents necessary to obtain the input data to choose the best solution is the schematic layout of the track system, the arrangement of devices in the control room, the type of devices and many more.

\section{Case study}

As part of the research, an example of operation of multicriteria method of selection the way of conducting railway traffic on the open line for modernized and revitalized railway lines was made. The analysis was carried out for the Ustronie Morskie station located on the single-track railway line No. 402 Koszalin Goleniów. This station conducts traffic on Ustronie Morskie - Mścice open line (direction Koszalin) and Ustronie Morskie - Kołobrzeg open line (direction Goleniów).

The railway line No. 402 is currently single-track. The assumption was made for the research that the situation will not change, and it will be a single-track line. Therefore, all variants were considered where single-track two-way traffic is possible [23]. These are $(v \in \mathbf{V})$ :

- telephone announcements of trains - single-track twoway train movement $(v=1)$,

- manual line block - single-track two-way train movement $(v=3)$,

- two-state automatic electric block system - single-track two-way train movement $(v=5)$,

- three-state automatic electric block system - singletrack two-way train movement $(v=7)$,

- four-state automatic electric block system - singletrack two-way train movement $(v=9)$.

Some partial criteria of the assessment were used to select the variant. These are $(c \in \mathbf{C})$ :

- time of agreement to accept the train $(c=1)$,

- time of receiving information about the departure of the train $(c=2)$,

- time of preparing the train entry $(c=3)$,

- preparation time of the path $(c=4)$, 
- driving surveillance $(c=5)$,

- end time of the path $(c=6)$,

- time of activities related to the end of the train entry $(c=7)$,

- time of announcing the arrival of the train $(c=8)$,

- time of requesting permission to send a train $(c=9)$,

- time of train departure preparation $(c=10)$,

- preparation time of the path $(c=11)$.

The values of evaluations of individual variants in relation to individual criteria are presented in Table 1. These values were determined based on consultations with the infrastructure manager PKP Polskie Linie Kolejowe expert, who works daily at the Ustronie Morskie station.

Table 1. Interval decision matrix (source: own work).

\begin{tabular}{|c|c|c|c|c|c|}
\hline & $v=1$ & $v=3$ & $v=5$ & $v=7$ & $v=9$ \\
\hline$c=1$ & {$[5 ; 10]$} & {$[11 ; 15]$} & {$[10 ; 15]$} & {$[10 ; 15]$} & {$[10 ; 15]$} \\
\hline$c=2$ & {$[20 ; 40]$} & {$[20 ; 40]$} & {$[10 ; 30]$} & {$[10 ; 30]$} & {$[10 ; 30]$} \\
\hline$c=3$ & {$[10 ; 40]$} & {$[10 ; 40]$} & {$[10 ; 20]$} & {$[10 ; 20]$} & {$[10 ; 20]$} \\
\hline$c=4$ & {$[5 ; 10]$} & {$[11 ; 15]$} & {$[10 ; 15]$} & {$[10 ; 15]$} & {$[10 ; 15]$} \\
\hline$c=5$ & {$[15 ; 30]$} & {$[15 ; 30]$} & {$[10 ; 30]$} & {$[10 ; 30]$} & {$[10 ; 30]$} \\
\hline$c=6$ & {$[10 ; 40]$} & {$[10 ; 40]$} & {$[10 ; 20]$} & {$[10 ; 20]$} & {$[10 ; 20]$} \\
\hline$c=7$ & {$[5 ; 7]$} & {$[3 ; 5]$} & {$[3 ; 5]$} & {$[3 ; 5]$} & {$[3 ; 5]$} \\
\hline$c=8$ & {$[5 ; 7]$} & {$[3 ; 5]$} & {$[1 ; 3]$} & {$[1 ; 3]$} & {$[1 ; 3]$} \\
\hline$c=9$ & {$[3 ; 5]$} & {$[5 ; 7]$} & {$[1 ; 3]$} & {$[1 ; 3]$} & {$[1 ; 3]$} \\
\hline$c=10$ & {$[3 ; 5]$} & {$[5 ; 7]$} & {$[1 ; 3]$} & {$[1 ; 3]$} & {$[1 ; 3]$} \\
\hline$c=11$ & {$[114 ; 265]$} & {$[126 ; 275]$} & {$[99 ; 215]$} & {$[99 ; 215]$} & {$[99 ; 215]$} \\
\hline
\end{tabular}

The normalized interval decision matrix is shown in Table 2. On its basis, the entropy, the level of variation and the objective weights of the criteria were determined as presented in Table 3 . The results obtained by the proposed SAW interval method with objective weights are shown in Table 4, where the results of linear combinations, elements of a normalized interval decision matrix (Table 2) and objective criteria weights (Table 3), and the ranking of decision variants are visible.

Table 2. Normalized interval decision matrix (source: own work).

\begin{tabular}{|c|c|c|c|c|c|}
\hline & $v=1$ & $v=3$ & $v=5$ & $v=7$ & $v=9$ \\
\hline$c=1$ & {$[0,04 ; 0,09]$} & {$[0,09 ; 0,13]$} & {$[0,09 ; 0,13]$} & {$[0,09 ; 0,13]$} & {$[0,09 ; 0,13]$} \\
\hline$c=2$ & {$[0,08 ; 0,18]$} & {$[0,08 ; 0,24]$} & {$[0,04 ; 0,18]$} & {$[0,04 ; 0,18]$} & {$[0,04 ; 0,18]$} \\
\hline$c=3$ & {$[0,05 ; 0,21]$} & {$[0,05 ; 0,21]$} & {$[0,05 ; 0,11]$} & {$[0,05 ; 0,11]$} & {$[0,05 ; 0,11]$} \\
\hline$c=4$ & {$[0,04 ; 0,09]$} & {$[0,09 ; 0,13]$} & {$[0,09 ; 0,13]$} & {$[0,09 ; 0,13]$} & {$[0,09 ; 0,13]$} \\
\hline$c=5$ & {$[0,07 ; 0,14]$} & {$[0,07 ; 0,14]$} & {$[0,05 ; 0,14]$} & {$[0,05 ; 0,14]$} & {$[0,05 ; 0,14]$} \\
\hline$c=6$ & {$[0,05 ; 0,08]$} & {$[0,08 ; 0,13]$} & {$[0,08 ; 0,13]$} & {$[0,08 ; 0,13]$} & {$[0,08 ; 0,13]$} \\
\hline$c=7$ & {$[0,06 ; 0,09]$} & {$[0,09 ; 0,13]$} & {$[0,09 ; 0,13]$} & {$[0,09 ; 0,13]$} & {$[0,09 ; 0,13]$} \\
\hline$c=8$ & {$[0,03 ; 0,04]$} & {$[0,04 ; 0,21]$} & {$[0,07 ; 0,21]$} & {$[0,07 ; 0,21]$} & {$[0,07 ; 0,21]$} \\
\hline$c=9$ & {$[0,04 ; 0,07]$} & {$[0,03 ; 0,04]$} & {$[0,07 ; 0,21]$} & {$[0,07 ; 0,21]$} & {$[0,07 ; 0,21]$} \\
\hline$c=10$ & {$[0,04 ; 0,07]$} & {$[0,03 ; 0,04]$} & {$[0,07 ; 0,21]$} & {$[0,07 ; 0,21]$} & {$[0,07 ; 0,21]$} \\
\hline$c=11$ & {$[0,06 ; 0,13]$} & {$[0,05 ; 0,12]$} & {$[0,07 ; 0,15]$} & {$[0,07 ; 0,15]$} & {$[0,07 ; 0,15]$} \\
\hline
\end{tabular}

Table 3. Entropy (e), level of variation (d) and objective weights (w) (source: own work).

\begin{tabular}{|c|c|c|c|}
\hline & e & $\mathbf{d}$ & $\mathbf{w}$ \\
\hline$c=1$ & {$[0,62 ; 0,79]$} & {$[0,21 ; 0,38]$} & {$[0,36 ; 0,64]$} \\
\hline$c=2$ & {$[0,50 ; 0,97]$} & {$[0,02 ; 0,50]$} & {$[0,05 ; 0,95]$} \\
\hline$c=3$ & {$[0,48 ; 0,85]$} & {$[0,15 ; 0,52]$} & {$[0,23 ; 0,77]$} \\
\hline$c=4$ & {$[0,62 ; 0,79]$} & {$[0,21 ; 0,38]$} & {$[0,36 ; 0,64]$} \\
\hline$c=5$ & {$[0,50 ; 0,86]$} & {$[0,14 ; 0,50]$} & {$[0,22 ; 0,78]$} \\
\hline$c=6$ & {$[0,48 ; 0,85]$} & {$[0,15 ; 0,52]$} & {$[0,23 ; 0,77]$} \\
\hline$c=7$ & {$[0,61 ; 0,80]$} & {$[0,20 ; 0,40]$} & {$[0,34 ; 0,66]$} \\
\hline
\end{tabular}

Table 3. Entropy (e), level of variation (d) and objective weights (w) (source: own work).

\begin{tabular}{|c|c|c|c|}
\hline & $\mathbf{e}$ & $\mathbf{d}$ & $\mathbf{w}$ \\
\hline$c=8$ & {$[0,49 ; 0,80]$} & {$[0,20 ; 0,512]$} & {$[0,28 ; 0,72]$} \\
\hline$c=9$ & {$[0,49 ; 0,80]$} & {$[0,20 ; 0,51]$} & {$[0,28 ; 0,72]$} \\
\hline$c=10$ & {$[0,49 ; 0,80]$} & {$[0,20 ; 0,51]$} & {$[0,28 ; 0,72]$} \\
\hline$c=11$ & {$[0,54 ; 0,85]$} & {$[0,15 ; 0,46]$} & {$[0,25 ; 0,75]$} \\
\hline
\end{tabular}

Table 4. Received results (source: own work).

\begin{tabular}{|c|c|c|}
\hline Variant & SAW & Rank \\
\hline$v=1$ & {$[0,138 ; 1,00]$} & 3 \\
\hline$v=3$ & {$[0,179 ; 1,113]$} & 2 \\
\hline$v=5$ & {$[0,199 ; 1,252]$} & 1 \\
\hline$v=7$ & {$[0,199 ; 1,252]$} & 1 \\
\hline$v=9$ & {$[0,199 ; 1,252]$} & 1 \\
\hline
\end{tabular}

The calculations show that variant 5,7 or 9 should be chosen - i.e. an automatic electric block system in twostate, three-state or four-state option.

\section{Summary and conclusions}

The aim of the article was to develop a multicriteria method of selection the way of conducting railway traffic on the open line for modernized and revitalized railway lines. It is very important problem because the more advanced the traffic system is, the more financial investment should be made.

The developed method takes into account many criteria that are expressed in units of time. These criteria describe the time of engagement of the person conducting the railway traffic (station inspector) in the performance of individual activities. Therefore, the assessment is made from the point of view of absorption of the station inspector. On the other hand, the developed method allows choosing the best solution from the point of view of the capacity of the lines and stations.

Summing individual times and multiplying by the number of trains that the station inspector must handle, we are able to estimate the capacity of the station, especially for peak hours. This allows us to obtain the number of trains that the station inspector is able to handle during the analysed time.

\section{References}

1. M. Andrzejewski, D. Gallas, P. Daszkiewicz, A. Merkisz-Guranowska, H. Stawecka, MATEC Web of Conferences, Volume: 118, Article Number: UNSP 00015 (2017)

2. P. Daszkiewicz, M. Andrzejewski, MATEC Web of Conferences, Volume: 118, Article Number: UNSP 00014 (2017)

3. S. Clarke, Work \& stress, 12(3), 285-292 (1998)

4. J. Santos-Reyes, A. N. Beard, Civil Engineering and Environmental Systems, 20(1), 1-21 (2003)

5. J. Santos-Reyes, A. N. Beard, R. A. Smith, Proceedings of the Institution of Mechanical Engineers, Part F: Journal of Rail and Rapid Transit, 219(2), 47-65 (2005) 
6. M. Sitarz, TTS Technika Transportu Szynowego, 19(5-6), 56-61 (2012)

7. M. Jacyna, P. Gołębiowski, D. Pyza, Archives of Transport System Telematics, 11(1), 27-33 (2018)

8. I. Jacyna-Gołda, J. Żak, P. Gołębiowski, Archives of Transport, 32(4), 17-28 (2014)

9. M. Bajerlein, L. Rymaniak, P. Swiatek, A. Ziolkowski, P. Daszkiewicz, M. Dobrzynski, Applied Mechanics and Materials, 518, 108-113 (2014).

10. J. Sysak (red.), Drogi kolejowe, Warszawa (1982)

11. Urząd Transportu Kolejowego, Sprawozdanie ze stanu bezpieczeństwa ruchu kolejowego w 2016 r., Warszawa (2017)

12. M. Jabłoński, A. Jabłoński, Zeszyty NaukowoTechniczne Stowarzyszenia Inżynierów i Techników Komunikacji w Krakowie. Seria: Materiały Konferencyjne, 2(104), 183-196 (2014)

13. M. Jacyna, P. Gołębiowski, M. Urbaniak, Communications in Computer and Information Science: Tools of Transport Telematics, 199-210 (2016)

14. J. Kwaśnikowski, G. Gramza, Analiza wybranych zakłóceń w ruchu kolejowym, Poznań (2007)

15. M. Jacyna, M. Izdebski, E. Szczepański, P. Gołda, Symmetry-Basel, 11(10), 1-19 (2018)
16. M. Jacyna, M. Wasiak, Communications in Computer and Information Science: Tools of Transport Telematics, 1-13 (2015)

17. M. Kiciński, K. Solecka, Archives of Transport, 46(2), 71-84 (2018)

18. T. Trzaskalik, Zeszyty Naukowe Politechniki Śląskiej. Seria: Organizacja i zarządzanie, 74, 239-263 (2014)

19. J. Żak, I. Jacyna-Gołda, Archives of Transport, 2526(1-2), 117-135 (2013)

20. R. Licow, F. Tomaszewski, Problemy Kolejnictwa, 171, 51-56 (2016)

21. Ustawa $z$ dnia 7 lipca 1994r. Prawo budowlane (Dz. U. z 2003r. Nr 207, poz. 2016 z późn. zm.)

22. A. Szeląg, Archives of Transport, 42(2), 75-83 (2017)

23. PKP Polskie Linie Kolejowe S.A., Instrukcja o prowadzeniu ruchu pociagów Ir-1, Warszawa (2017)

24. D. Kacprzak, Studia Ekonomiczne. Zeszyty Naukowe Uniwersytetu Ekonomicznego w Katowicach, 348, 144-155 (2018)

25. F. Lotfi, R. Fallahnejad, Entropy, 12, 53-62 (2010) 